\title{
BMJ Open The biomechanics of concussion in unhelmeted football players in Australia: a case-control study
}

\author{
Andrew S Mclntosh, ${ }^{1,2}$ Declan A Patton, ${ }^{3}$ Bertrand Fréchède, ${ }^{4,5,6}$ \\ Paul-André Pierré, ${ }^{7}$ Edouard Ferry, ${ }^{8}$ Tobias Barthels ${ }^{9}$
}

To cite: Mclntosh AS, Patton DA, Fréchède $B$, et al. The biomechanics of concussion in unhelmeted football players in Australia: a case-control study. BMJ Open 2014;4:e005078. doi:10.1136/bmjopen-2014005078

- Prepublication history and additional material is available. To view please visit the journal (http://dx.doi.org/ 10.1136/bmjopen-2014005078).

Received 17 February 2014 Revised 1 April 2014 Accepted 7 April 2014

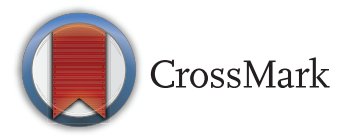

For numbered affiliations see end of article.

Correspondence to Dr Andrew S McIntosh; as.mcintosh@bigpond.com.

\section{ABSTRACT}

Objective: Concussion is a prevalent brain injury in sport and the wider community. Despite this, little research has been conducted investigating the dynamics of impacts to the unprotected human head and injury causation in vivo, in particular the roles of linear and angular head acceleration.

Setting: Professional contact football in Australia. Participants: Adult male professional Australian rules football players participating in 30 games randomly selected from 103 games. Cases selected based on an observable head impact, no observable symptoms (eg, loss-of-consciousness and convulsions), no on-field medical management and no injury recorded at the time.

Primary and secondary outcome measures: $A$ data set for no-injury head impact cases comprising head impact locations and head impact dynamic parameters estimated through rigid body simulations using the MAthematical DYnamic MOdels (MADYMO) human facet model. This data set was compared to previously reported concussion case data.

Results: Qualitative analysis showed that the head was more vulnerable to lateral impacts. Logistic regression analyses of head acceleration and velocity components revealed that angular acceleration of the head in the coronal plane had the strongest association with concussion; tentative tolerance levels of $1747 \mathrm{rad} / \mathrm{s}^{2}$ and $2296 \mathrm{rad} / \mathrm{s}^{2}$ were reported for a $50 \%$ and $75 \%$ likelihood of concussion, respectively. The mean maximum resultant angular accelerations for the concussion and no-injury cases were $7951 \mathrm{rad} / \mathrm{s}^{2}$ (SD $\left.3562 \mathrm{rad} / \mathrm{s}^{2}\right)$ and $4300 \mathrm{rad} / \mathrm{s}^{2}\left(\mathrm{SD} 3657 \mathrm{rad} / \mathrm{s}^{2}\right)$, respectively. Linear acceleration is currently used in the assessment of helmets and padded headgear. The $50 \%$ and $75 \%$ likelihood of concussion values for resultant linear head acceleration in this study were 65.1 and $88.5 \mathrm{~g}$, respectively.

Conclusions: As hypothesised by Holbourn over 70 years ago, angular acceleration plays an important role in the pathomechanics of concussion, which has major ramifications in terms of helmet design and other efforts to prevent and manage concussion.

\section{INTRODUCTION}

Concussion has been identified as the most commonly occurring brain injury seen

\section{Strengths and limitations of this study}

- The study presents human tolerance estimates for concussion based on linear and angular head acceleration from impacts in which participants do not wear helmets.

- The study highlights the value of considering the location of the head impact in the on-field or sideline assessment of concussion.

- The study confirms the similarity in concussion tolerance levels across a range of contact sports, including those with and without helmets.

- Estimates of the head impact dynamics were made using computer reconstructions of impacts sampled using defined criteria from a random sample of games. Head impact dynamics were not measured using a wearable device.

- The study does not present exposure adjusted impact and injury data.

throughout the world, ${ }^{1}$ especially in sports, with over half of all concussions being sport related $^{2}$ and $9 \%$ of all sporting injuries thought to be concussions. ${ }^{3}$ Concussion has been defined as 'a complex pathophysiological process affecting the brain, induced by traumatic biomechanical forces' ${ }^{4}$ Early in vivo biomechanical studies of concussion examined the effects of impacts on primates ${ }^{5}$; however, such studies were limited biomechanically, due to neuroanatomical differences between primates and humans, and clinically, due to the complex range of signs and symptoms of concussion. ${ }^{1}$ Concussion studies have been conducted on helmeted ${ }^{6-25}$ and unhelmeted ${ }^{26-28}$ football players. Initial studies focused on concussion impacts using qualitative and biomechanical methods. ${ }^{6-9} 2628$ Recently, the use of instrumented helmets in American football and ice hockey have enabled the measurement of the head kinematics during 'subconcussive' and no-injury head impacts ${ }^{13-25}$; however, such studies have identified that the ability of peak linear acceleration alone to predict 
concussion is limited. For example, the study of concussion in American football carried out by Greenwald et $a l^{19}$ found that only $0.3 \%$ of impacts that recorded peak linear head acceleration of greater than $98.9 \mathrm{~g}$ resulted in concussion, which represents a $75 \%$ probability of concussion according to the analysis by Pellman et al. ${ }^{9}$ Using instrumented helmets, Funk et al ${ }^{15}$ observed that 516 head impacts, from a total of 37128 recorded in collegiate American football, had exceeded $100 \mathrm{~g}$; however, only four players experienced a concussion. One explanation for this discrepancy is the role of angular acceleration on brain loading; a view that extends back 70 years to the hypothesis of Holbourn, ${ }^{29}$ which states that rotational kinematics were the main cause of shear strains in brain tissue and, therefore, indicative of the probability of injury.

Kleiven ${ }^{11}$ analysed 58 helmeted American football head impact cases using the KTH Finite Element (FE) Human Head Model and observed that a combination of the Head Injury Criterion and change in angular velocity of the head provided the best correct classification of concussion incidence for the sample. Kleiven ${ }^{11}$ also observed that the rotational kinematics of the head were the most important factor in determining the intracranial strain, whereas linear kinematics determined intracranial pressure. Zhang et $a l^{10}$ analysed 24 helmeted American football head impact cases using the Wayne State University Brain Injury Model (WSUBIM). Strong correlations were observed between angular acceleration and shear stresses in the brain, especially at the brainstem, and linear acceleration and intracranial pressure; however, a poor correlation was observed between linear acceleration and shear stress. In a sophisticated series of cadaver head impact experiments, Hardy et $a \hat{l}^{0}$ made similar observations regarding the relationship between linear acceleration and intracranial pressure. Hardy et $a \vec{l}^{0}$ also observed that brain motion patterns are associated with angular velocity; however, no significant relationship between angular acceleration and intracerebral strain was found. One limitation of the study by Hardy et $a l^{30}$ in comparison to $\mathrm{FE}$ methods, was that the targets used for measuring intracranial strain were in discrete locations in the cerebral cortex. Guskiewicz et $a l^{16}$ observed no correlation between peak linear or angular acceleration of the head, as measured by instrumented helmets, and concussion symptoms in 13 concussion cases from a sample of 88 collegiate American football players; however, Guskiewicz et $a l^{16}$ did not control for impact location. McCaffrey et $a{ }^{17}{ }^{17}$ using a similar cohort of 43 collegiate American football players fitted with instrumented helmets, did not observe that head impacts resulting in a maximum acceleration greater than $90 \mathrm{~g}$ resulted in observable changes to balance or neurocognitive function. More recently, Rowson $e t a l^{24}$ analysed head impacts measured using instrumented helmets and observed a $50 \%$ likelihood of concussion associated with a resultant angular acceleration of $6383 \mathrm{rad} / \mathrm{s}^{2}$ and resultant angular velocity of $28.3 \mathrm{rad} / \mathrm{s}$.
Rowson and Duma ${ }^{31}$ later developed a new metric, the Combined Probability of Concussion (CPC), which combines the peak resultant linear and angular acceleration from a database of no-injury and concussion head impacts recorded using instrumented helmets. ${ }^{16} 2124$ Another database of head impacts recorded using instrumented helmets, in addition to the anthropomtric test device (ATD) reconstructions of Newman $e t a l,{ }^{6-8}$ were used to assess the predictive capability of the CPC, which was found to be a significantly better predictor in comparison to peak resultant angular acceleration.

In contrast to the cited studies on American football and ice hockey, helmets are not typically worn in professional football codes in Australia; therefore, this research provides opportunities to examine concussion in the unhelmeted athlete in vivo. A fundamental understanding of human tolerance to head impacts is a prerequisite for the evaluation of concussion risk and the design of methods, such as helmets, to mitigate those risks. ${ }^{32}$ The specific aims of the study were to (1) investigate the dynamics, impact location and kinematics, of no-injury and concussive impacts to the unprotected human head and (2) consider concussion tolerance values.

\section{MATERIALS AND METHODS}

Video of 103 Australian rules football games, from the same period (1995-1998) and cohort as an earlier study that analysed Australian rules football concussion cases, ${ }^{26}$ were collated. Thirty games were randomly selected after assigning numbers to each of the 103 games and making the selection using a random number generator. No-injury head impact cases in each game were selected using the following criteria: an observable head impact, no observable symptoms (eg, loss-of-consciousness, convulsions, etc), no on-field medical management and no resultant injury recorded at the time. Despite these selection criteria, players may have exhibited signs or symptoms of concussion, for example, headache, and not reported them. Each head impact case was assessed for impact location (frontal, temporal, parietal, occipital, crown or face).

A total of 122 no-injury head impact cases (the reference group) were identified and analysed qualitatively from the 30 games (figure 1). The 122 no-injury cases were then reviewed to assess which cases could be analysed further; initially to obtain the two-dimensional kinematic data and finally head impact kinematics through rigid body reconstructions. The review consisted of assessing each image sequence against the selection criteria, which included zooming, panning, oblique camera angles, video quality and calibration objects, as per previously established methods. ${ }^{26}$ The majority of video sequences were excluded from quantitative analysis because they failed to meet the selection criteria. Only 13 no-injury head impact cases met the selection criteria and were deemed suitable for reconstruction and kinematic analysis. Bias in selecting the no-injury 


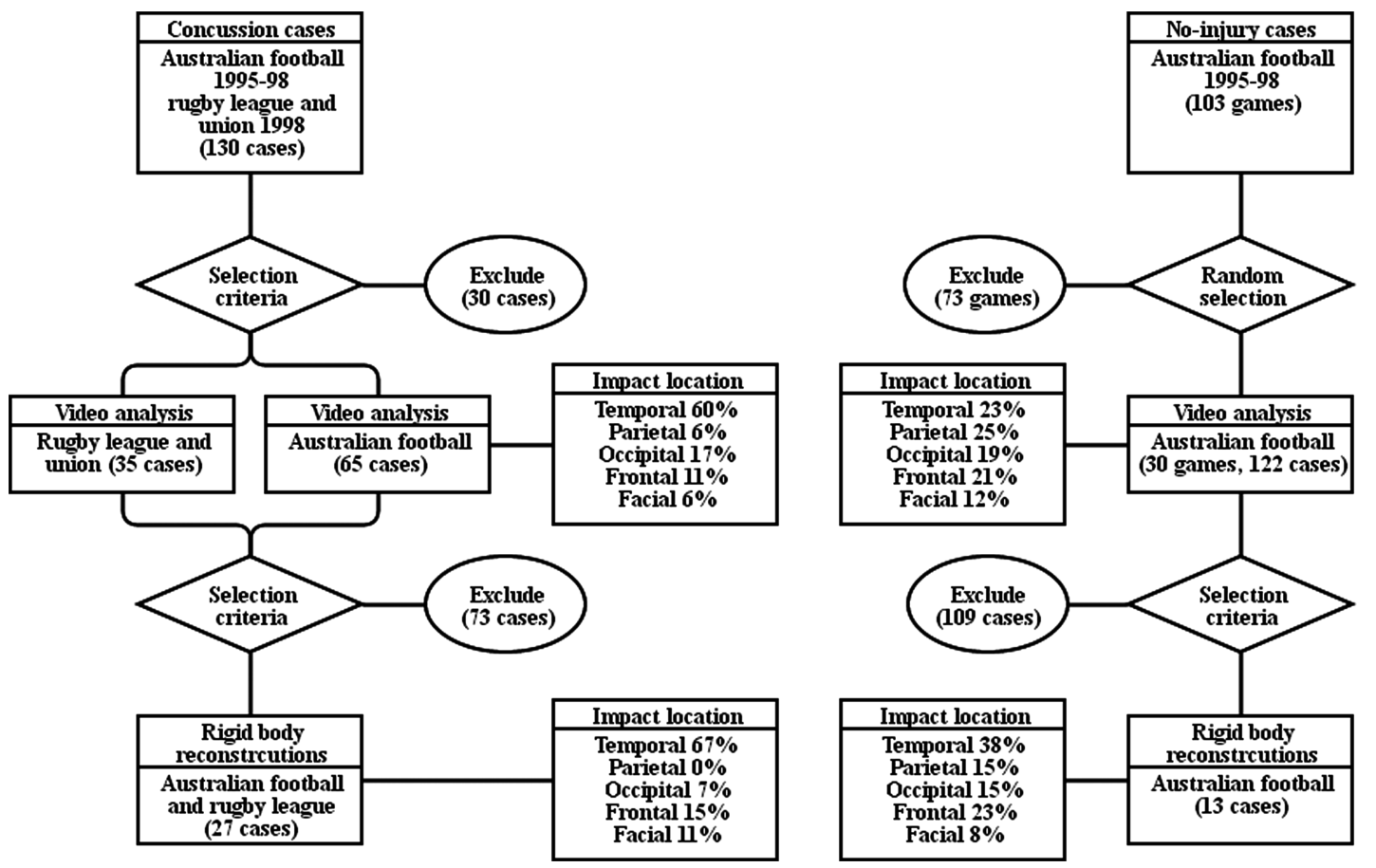

Figure 1 Flow chart of concussion and no-injury case selection. The rigid body reconstruction concussion cases comprised 23 Australian football and 4 rugby league cases. ${ }^{28}$ Australian football is also referred to in the text as Australian rules football.

cases was minimised by randomly selecting the games, identifying all no-injury head impacts and only reconstructing the events that met the predefined selection criteria.

In order to estimate the head's three-dimensional kinematics, including linear and angular acceleration, the 13 suitable no-injury cases were reconstructed using methods reported by Fréchède and McIntosh ${ }^{28}$ The following is a detailed summary of these methods and further notes are provided in online supplementary appendix A. The reconstructions were simulated using the MAthematical DYnamic MOdels (MADYMO) human facet model, which is widely used in the automotive industry as a pedestrian or seated occupant. The behaviour of the model had previously been validated for blunt impacts at various locations, but not for the head. The contact properties of the head were refined and validated using published data from cadaver impact experiments and FE simulations. ${ }^{33-35}$ The masses and inertias of body segments were scaled to the known anthropometry of the players, using the GEnerator of BOdy Dimensions (GEBOD) scaling equations, ${ }^{36}$ and lumped into the models. Initially, the models were positioned in the same relative orientation as they were just prior to impact in the game footage and a state of generic muscular activation was applied by adding joint restraint torques. ${ }^{28}$ The initial position, body segment velocities and joint restraint torques were adjusted to correctly match the kinematic behaviour of the simulation with the video event. Through this process, two datasets were derived each containing the reference group (no-injury head impacts) and cases (concussive head impact): (1) 187 events with a description of head impact location and impacting object (65 Australian rules football concussion cases and 122 Australian rules football no-injury cases) and (2) 40 reconstructed head impact cases (13 no-injury and 27 concussion). The 27 concussion cases included in this paper had been selected from a larger database of 100 concussion cases, as per the methods detailed in Fréchède and McIntosh ${ }^{27}$ which had previously been analysed quantitatively and qualitatively by McIntosh et $a l^{26}$

For all 40 reconstructed head impact cases, the orthogonal component profiles of linear and angular accelerations were extracted and the angular acceleration curves were integrated in order to obtain the angular velocity component and resultant profiles. The orthogonal components were defined in a head-based coordinate axis system with the origin at the centre-of-gravity: $+\mathrm{X}$, anterior; $+\mathrm{Z}$, superior; $+\mathrm{Y}$, lateral (left). Peak linear acceleration, angular acceleration and angular velocity were calculated for resultants and all unique directional components.

The influence of location of impact on concussion was first assessed using a $\chi^{2}$ analysis. Statistical $t$ tests were used to analyse the mean kinematic values of the concussion and no-injury cases; the results were compared to previous concussion studies in American football and ice hockey. $^{6-8} 12-161820212324$ Univariate logistic regression analyses were performed with the occurrence of concussion as the dichotomous dependent variable. All resultant and unique component kinematic parameters were analysed as independent variables: linear acceleration, angular velocity and angular acceleration. Linear 
velocity and impact location were not included in the regression analyses. A commercially available statistical software package, PASW Statistics V.18.0, ${ }^{37}$ was used to perform the logistic regression analysis. The log-likelihood ratio statistic and significance test was used for overall model evaluation ${ }^{38}$ as it is generally considered to be the superior inferential test, especially for small sample sizes. ${ }^{39}{ }^{40}$ Nagelkerke $^{41}$ generalised the coefficient of determination $\left(\mathrm{R}^{2}\right)$, a concept defined for ordinary least squares regression, for use in logistic regression as a supplementary goodness-of-fit index. The index is interpreted as improvement from the null model to the parameter model and ranges from 0 to 1 . The Nagelkerke pseudo- $\mathrm{R}^{2}$ index, in addition to the percentage correct classification, was used to assess the goodness-of-fit of the models.

\section{RESULTS}

In the 30 games reviewed 122 no-injury head impact cases were observed and coded for impact location, impacting object and potential for quantitative analysis. A comparison was made between the head impact location and object striking the head for 122 non-injury cases and the 65 concussion head impact cases, which were previously reported by McIntosh et al. ${ }^{26}$ There was a significant difference $(p<0.001)$ in head impact location between concussion and no-injury head impact cases. The proportion of impacts to the temporal region was significantly greater $(\mathrm{p}=0.05)$ for concussion cases compared to no-injury cases, $60-23 \%$, respectively. The proportions of impacts for concussion cases were also compared to no-injury cases for other impact sites: parietal, 6-25\%; occipital, 17-19\%; frontal, 11-21\%; facial, $6-12 \%$, respectively. There were no crown impacts for either no-injury or concussion cases. No significant differences were observed between the objects striking the head for concussion and no-injury cases.

Only 13 of the 122 no-injury head impact cases met the criteria for further quantitative analysis and reconstruction, which required minimal parallax error in the impact video and presence of scaling methods, and reconstruction. After deriving the closing speeds of the players from the video, the head impact dynamics of 13 cases were then reconstructed using MADYMO. The no-injury results were compared to 27 medically verified concussion cases that had previously been analysed using these methods. ${ }^{28}$

A significant difference $(p=0.001)$, for mean peak linear acceleration between concussion, $103.4 \mathrm{~g}$ (SD $29.5 \mathrm{~g}$ ), and no-injury, $59.0 \mathrm{~g}$ (SD $37.2 \mathrm{~g}$ ), head impacts for the resultant (R) was observed (figure 2 and table 1 ). The mean peak inferior components of linear acceleration $(-Z)$ also had a significant difference $(p<0.001)$ between concussion, 32.4 g (SD 24.6 g) and no-injury, $11.6 \mathrm{~g}(\mathrm{SD} 8.9 \mathrm{~g})$, cases.

For peak angular accelerations in the coronal plane (X), a significant difference $(p<0.001)$ was found between the

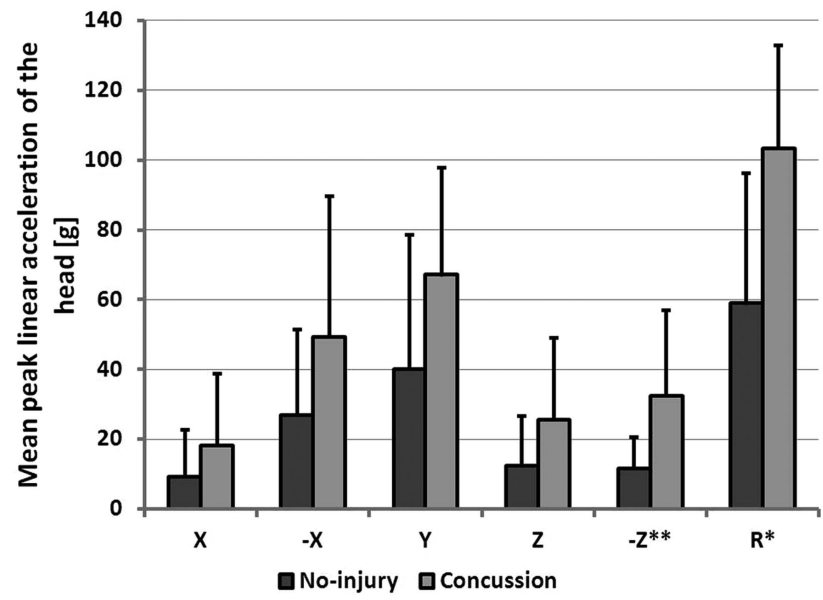

Figure 2 Mean peak linear acceleration of the head, for all unique directional components $(X,-X, Y, Z,-Z)$ and resultant (R). Significance levels: ${ }^{*} p<0.01,{ }^{* *} p<0.001$ (two-sample t test for unequal variance). Error bars represent one SD.

means of the concussion, $4823 \mathrm{rad} / \mathrm{s}^{2}\left(\mathrm{SD} 2096 \mathrm{rad} / \mathrm{s}^{2}\right)$ and no-injury, $1548 \mathrm{rad} / \mathrm{s}^{2}\left(\mathrm{SD} 1029 \mathrm{rad} / \mathrm{s}^{2}\right)$, cases (figure 3). A significant difference $(p<0.001)$ was also observed between concussion, $5144 \mathrm{rad} / \mathrm{s}^{2}\left(\mathrm{SD} 2800 \mathrm{rad} / \mathrm{s}^{2}\right)$ and no-injury, $2523 \mathrm{rad} / \mathrm{s}^{2}$ (SD $\left.1753 \mathrm{rad} / \mathrm{s}^{2}\right)$, head impacts for the peak transverse plane $(\mathrm{Z})$ components of angular acceleration. A significant difference $(p=0.001)$, for mean peak resultant angular acceleration, between concussion, $7951 \mathrm{rad} / \mathrm{s}^{2}$ (SD $3562 \mathrm{rad} / \mathrm{s}^{2}$ ) and no-injury, $4300 \mathrm{rad} / \mathrm{s}^{2}$ (SD $\left.3657 \mathrm{rad} / \mathrm{s}^{2}\right)$, head impacts was observed (figure 2 and table 2).

A significant difference $(p<0.001)$ was observed for mean peak angular velocity of the head, for the resultant (R) between concussion, $36.1 \mathrm{rad} / \mathrm{s}$ (SD $12.0 \mathrm{rad} / \mathrm{s})$, and no-injury, $18.4 \mathrm{rad} / \mathrm{s}$ (SD $7.6 \mathrm{rad} / \mathrm{s}$ ), cases (figure 4). A difference with a similar level of significance $(\mathrm{p}<0.001)$ was found between concussion, $23.1 \mathrm{rad} / \mathrm{s}$ (SD $11.3 \mathrm{rad} / \mathrm{s}$ ), and no-injury, $8.8 \mathrm{rad} / \mathrm{s}$ ( $S D 5.5 \mathrm{rad} / \mathrm{s}$ ), head impacts for the coronal plane (X) components of mean peak angular velocity. Peak angular velocity of the head in the transverse plane $(Z)$ also had a significant difference $(\mathrm{p}=0.005)$ between concussion, $21.8 \mathrm{rad} / \mathrm{s}$ (SD $12.4 \mathrm{rad} / \mathrm{s}$ ) and no-injury, $12.2 \mathrm{rad} / \mathrm{s}$ (SD $7.6 \mathrm{rad} / \mathrm{s}$ ), cases.

Logistic regression analyses of the kinematic parameters demonstrated that angular acceleration of the head in the coronal plane had the strongest association with concussion (table 3). This parameter was both sensitive and specific, with the predicted percentage correct classifications for no-injury and concussion cases being $92.3 \%$ and $92.6 \%$, respectively. The $50 \%$ and $75 \%$ likelihood of concussion values for head angular acceleration in the coronal plane were 1747 and $2296 \mathrm{rad} / \mathrm{s}^{2}$, respectively.

\section{DISCUSSION}

The results of the current study suggest that concussion is more commonly associated with impacts to the 
Table 1 Comparison of mean peak resultant linear head accelerations, for concussion and no-injury cases, reported in the literature

\begin{tabular}{|c|c|c|c|c|c|c|c|}
\hline \multirow[b]{2}{*}{ Study } & \multicolumn{2}{|c|}{$\begin{array}{l}\text { Mean peak resultant } \\
\text { linear head } \\
\text { acceleration (g) }\end{array}$} & \multicolumn{2}{|c|}{ Number of cases } & \multirow[b]{2}{*}{ Sport } & \multirow[b]{2}{*}{ Level } & \multirow[b]{2}{*}{ Method } \\
\hline & No-injury & Concussion & No-injury & Concussion & & & \\
\hline Naunheim et $a^{12}$ & 29.2 & - & 132 & 0 & American football & High school & $\begin{array}{l}\text { Instrumented } \\
\text { helmets }\end{array}$ \\
\hline Newman et $a^{\rho^{-8}}$ & 54.3 & 97.9 & 33 & 25 & American football & Professional & $\begin{array}{l}\text { ATD } \\
\text { reconstructions }\end{array}$ \\
\hline Duma et $a l^{13}$ & 32.0 & 81 & 3311 & 1 & American football & Collegiate & $\begin{array}{l}\text { Instrumented } \\
\text { helmets }\end{array}$ \\
\hline Brolinson et al ${ }^{14}$ & 20.1 & 103.3 & 11601 & 3 & American football & Collegiate & $\begin{array}{l}\text { Instrumented } \\
\text { helmets }\end{array}$ \\
\hline Funk et $a l^{15}$ & - & 151 & 22701 & 3 & American football & Collegiate & $\begin{array}{l}\text { Instrumented } \\
\text { helmets }\end{array}$ \\
\hline $\begin{array}{l}\text { Guskiewicz } \\
\text { et } a l^{16}\end{array}$ & - & 102.8 & 0 & 13 & American football & Collegiate & $\begin{array}{l}\text { Instrumented } \\
\text { helmets }\end{array}$ \\
\hline Schnebel et al ${ }^{18}$ & - & 105.9 & 0 & 3 & American football & $\begin{array}{l}\text { High school, } \\
\text { collegiate }\end{array}$ & $\begin{array}{l}\text { Instrumented } \\
\text { helmets }\end{array}$ \\
\hline Broglio $^{20}$ & 25.0 & - & 19224 & 0 & American football & High school & $\begin{array}{l}\text { Instrumented } \\
\text { helmets }\end{array}$ \\
\hline Broglio et $a f^{1}$ & 25.1 & - & 54247 & 0 & American football & High school & $\begin{array}{l}\text { Instrumented } \\
\text { helmets }\end{array}$ \\
\hline McAllister et $a^{R^{3}}$ & - & 73.6 & 0 & 10 & $\begin{array}{l}\text { American football, } \\
\text { ice hockey }\end{array}$ & $\begin{array}{l}\text { High school, } \\
\text { collegiate }\end{array}$ & $\begin{array}{l}\text { Instrumented } \\
\text { helmets }\end{array}$ \\
\hline Rowson et a ${ }^{4}$ & - & 103 & 300977 & 57 & American football & Collegiate & $\begin{array}{l}\text { Instrumented } \\
\text { helmets }\end{array}$ \\
\hline Current study & 59.0 & 103.4 & 13 & 27 & $\begin{array}{l}\text { Australian rules } \\
\text { football, rugby } \\
\text { leaque }\end{array}$ & Professional & $\begin{array}{l}\text { Rigid body } \\
\text { simulations }\end{array}$ \\
\hline
\end{tabular}

temporal region of the head and angular kinematics of the head in the coronal plane. In these cases, such impacts also resulted in linear acceleration of the head. A biomechanical association exists between temporal impacts and coronal plane angular kinematics. Although

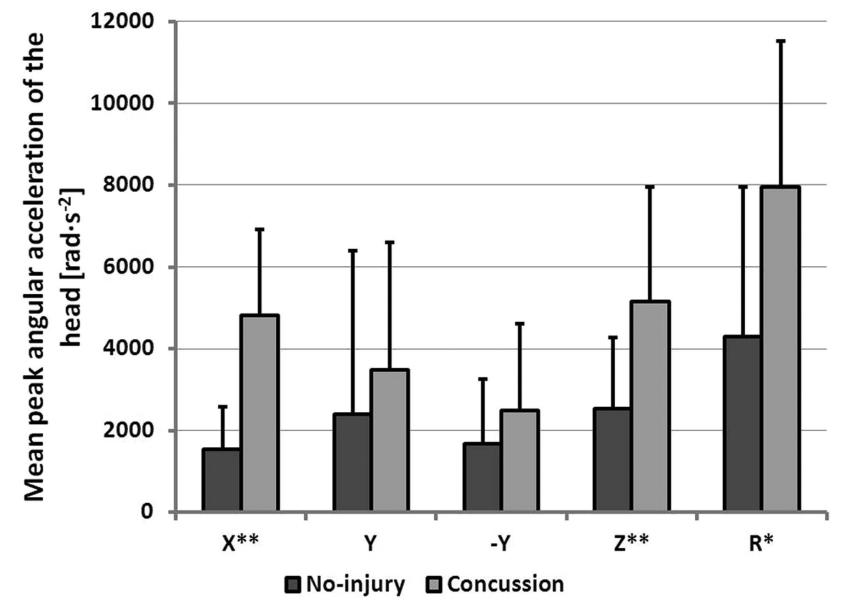

Figure 3 Mean peak angular acceleration of the head, for all unique directional components $(X, Y,-Y, Z)$ and resultant $(R)$. Significance levels: ${ }^{*} p<0.01,{ }^{* *} p<0.001$ (two-sample $t$ test for unequal variance). Error bars represent one SD. it is unlikely, there is a possibility that temporal impacts were more forceful than other impacts due to the nature of the game and the phases of play in which players were injured. It is also possible that the impacted player was unaware of the impending contact prior a temporal impact, in contrast to frontal impacts, which occur in a player's direct field of vision. However, there is currently no evidence that neck strength is protective against concussion. ${ }^{42}$ American football studies using instrumented helmets have found that impacts to the front, top and back of the head were associated with injury $^{19} 21$; however, in the current study, impacts to the temporal region were found to be associated with concussion. The difference in results may be due to the different structure of the two games or the use of helmets in American football.

The dataset of 40 reconstructed concussions and no-injury head impact cases analysed in this paper is most comparable to the set of 58 cases by Newman et $a l^{6-8}$; however, Newman et $a l^{6-8}$ analysed helmeted impacts, used physical tests to reconstruct the impacts and used paired head-to-head impacts for the concussion and no-injury cases.

The mean maximum linear acceleration for the concussion cases in the current study, $103.4 \mathrm{~g}$ (SD 29.5 g), was within the range of results, 73.6-151 g (table 1), 
Table 2 Comparison of mean peak resultant angular head accelerations, for concussion and no-injury cases, reported in the literature

\begin{tabular}{|c|c|c|c|c|c|c|c|}
\hline \multirow[b]{2}{*}{ Study } & \multicolumn{2}{|c|}{$\begin{array}{l}\text { Mean peak resultant } \\
\text { angular head } \\
\text { acceleration }\left(\mathrm{rad} / \mathrm{s}^{2}\right)\end{array}$} & \multicolumn{2}{|c|}{ Number of cases } & \multirow[b]{2}{*}{ Sport } & \multirow[b]{2}{*}{ Level } & \multirow[b]{2}{*}{ Method } \\
\hline & No-injury & Concussion & No-injury & Concussion & & & \\
\hline Newman et $a \rho^{6-8}$ & 4159 & 6664 & 33 & 25 & American football & Professional & $\begin{array}{l}\text { ATD } \\
\text { reconstructions }\end{array}$ \\
\hline Duma et $a l^{13}$ & - & 7912 & 3311 & 1 & American football & Collegiate & $\begin{array}{l}\text { Instrumented } \\
\text { helmets }\end{array}$ \\
\hline $\begin{array}{l}\text { Guskiewicz } \\
\text { et al }{ }^{16}\end{array}$ & - & 5312 & 0 & 13 & American football & Collegiate & $\begin{array}{l}\text { Instrumented } \\
\text { helmets }\end{array}$ \\
\hline Broglio et $a{ }^{21}$ & 1627 & - & 54247 & 0 & American football & High school & $\begin{array}{l}\text { Instrumented } \\
\text { helmets }\end{array}$ \\
\hline McAllister et $a^{23}$ & - & 5025 & 0 & 10 & $\begin{array}{l}\text { American football, } \\
\text { ice hockey }\end{array}$ & $\begin{array}{l}\text { High school, } \\
\text { collegiate }\end{array}$ & $\begin{array}{l}\text { Instrumented } \\
\text { helmets }\end{array}$ \\
\hline Rowson et $a^{24}$ & 1230 & 5022 & 300977 & 57 & American football & Collegiate & $\begin{array}{l}\text { Instrumented } \\
\text { helmets }\end{array}$ \\
\hline Current study & 4300 & 7951 & 13 & 27 & $\begin{array}{l}\text { Australian rules } \\
\text { football, rugby } \\
\text { league }\end{array}$ & Professional & $\begin{array}{l}\text { Rigid body } \\
\text { simulations }\end{array}$ \\
\hline
\end{tabular}

reported by previous studies, ${ }^{6-8} \quad 12-14 \quad 16 \quad 18 \quad 202124$ with several reporting values close to 100 g. ${ }^{6-8} 14161824$ Apart from the players not wearing helmets, there were differences between studies in sample size, biomechanical methods, selection criteria for no-injury cases and competition level. For the current study, all players were adult male professional athletes like those studied by Newman et $a l^{6-8}$; however, the instrumented helmet studies assessed high school and collegiate players. In the instrumented helmet studies, ${ }^{13} 141618202124$ all impacts that exceeded a predefined threshold were recorded, while Newman et $a l^{6-8}$ used paired cases and the current study used a predetermined selection criteria for no-injury cases. For no-injury cases, the mean maximum linear acceleration in the current study, $59.0 \mathrm{~g}$ (SD $37.2 \mathrm{~g}$ ), was

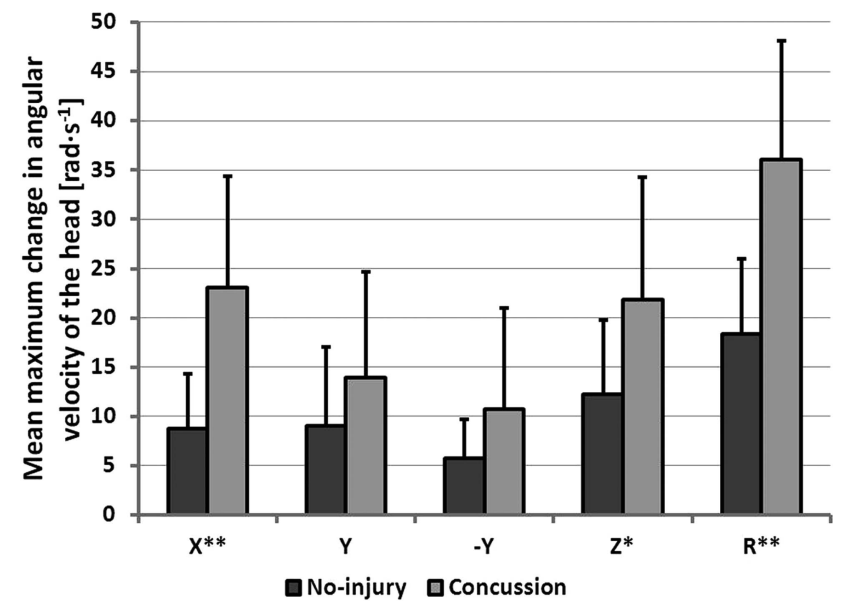

Figure 4 Mean peak angular velocity of the head, for all unique directional components $(X, Y,-Y, Z)$ and resultant $(R)$. Significance levels: ${ }^{*} p<0.01,{ }^{* *} p<0.001$ (two-sample $t$ test for unequal variance). Error bars represent one SD. higher than the range of results, 19.0-54.3 $\mathrm{g}$ (table 1), reported by previous studies. $^{6-8} \quad 12-14162021$ This difference is influenced strongly by the no-injury case selection criteria, for example, the acceleration threshold applied in the instrumented helmets to record an impact will affect the mean acceleration of no-injury impacts whereas in the current study, only clearly observable head impacts were analysed.

The study by McAllister et $a l^{23}$ was the only previous study to report the components of linear acceleration for concussion cases. In the current study, the inferior component of linear acceleration $(-\mathrm{Z})$ had significant differences $(\mathrm{p}<0.001)$ between concussion and no-injury cases (figure 1), with a mean peak acceleration of $32.4 \mathrm{~g}$ (SD $24.6 \mathrm{~g}$ ) for concussion cases. This value compared well to the mean peak acceleration of $35.4 \mathrm{~g}$ reported by McAllister et $a l^{23}$ for 10 concussion cases recorded using instrumented helmets. Rowson et $a l^{25}$ reported the mean values of linear acceleration components for 1712 no-injury impacts recorded during collegiate American football: anterior-posterior, $12.8 \mathrm{~g}$; medial-lateral, $10.0 \mathrm{~g}$ and superior-inferior, $16.5 \mathrm{~g}$. The mean superior-inferior value reported by Rowson et $a{ }^{25}{ }^{25} 16.5 \mathrm{~g}$, was similar to the no-injury mean value found in the current study, $16.2 \mathrm{~g}$; however, the anterior-posterior and medial-lateral values were higher in the current study: 32.8 and $40.1 \mathrm{~g}$, respectively. Once again this difference may be influenced strongly by the no-injury case selection criteria and the nature of the two different football codes.

Linear acceleration is currently used in the assessment of helmets and padded headgear. ${ }^{32}$ The $50 \%$ and $75 \%$ likelihood of concussion values for resultant linear head acceleration in this study were 65.1 and $88.5 \mathrm{~g}$, respectively (table 3 ). These levels are indicative of the extent to which helmets are required to manage linear 
Table 3 Summary of logistic regression analysis of kinematic injury predictors, significantly associated with concussion $(p<0.001)$, ranked using the likelihood ratio test, pseudo- $R^{2}$ and percentage correct classification statistics

\begin{tabular}{|c|c|c|c|c|c|c|}
\hline \multirow[b]{2}{*}{ Variable } & \multicolumn{2}{|c|}{$\begin{array}{l}-2 \text { Log } \\
\text { likelihood } \\
\text { ratio }\end{array}$} & \multirow{2}{*}{$\begin{array}{r}\text { Nagelkerke } \\
\text { Pseudo- }^{2}\end{array}$} & \multirow{2}{*}{$\begin{array}{l}\text { Percentage correct } \\
\text { Classification (\%) }\end{array}$} & \multicolumn{2}{|c|}{$\begin{array}{l}\text { Concussion likelihood } \\
\text { values }\end{array}$} \\
\hline & $\chi^{2}$ & p Value & & & $50 \%$ & $75 \%$ \\
\hline Angular acceleration (coronal plane) & 26.8 & $<0.001$ & 0.68 & 92.5 & $1747 \mathrm{rad} / \mathrm{s}^{2}$ & $2296 \mathrm{rad} / \mathrm{s}^{2}$ \\
\hline Angular velocity (resultant) & 21.9 & $<0.001$ & 0.59 & 80.0 & $22.2 \mathrm{rad} / \mathrm{s}$ & $27.5 \mathrm{rad} / \mathrm{s}$ \\
\hline Angular velocity (coronal plane) & 18.8 & $<0.001$ & 0.52 & 85.0 & $10.8 \mathrm{rad} / \mathrm{s}$ & $15.9 \mathrm{rad} / \mathrm{s}$ \\
\hline Linear acceleration (resultant) & 14.8 & $<0.001$ & 0.43 & 82.5 & $65.1 \mathrm{~g}$ & $88.5 \mathrm{~g}$ \\
\hline Linear acceleration (inferior component) & 14.1 & $<0.001$ & 0.41 & 77.5 & $12.3 \mathrm{~g}$ & $20.7 \mathrm{~g}$ \\
\hline Angular acceleration (transverse plane) & 12.3 & $<0.001$ & 0.37 & 80.0 & $1909 \mathrm{rad} / \mathrm{s}^{2}$ & $3008 \mathrm{rad} / \mathrm{s}^{2}$ \\
\hline Angular acceleration (resultant) & 10.2 & $<0.001$ & 0.31 & 82.5 & $3958 \mathrm{rad} / \mathrm{s}^{2}$ & $6633 \mathrm{rad} / \mathrm{s}^{2}$ \\
\hline
\end{tabular}

acceleration in an impact if they are to reduce the likelihood of concussion. One reason why helmets or padded headgear may not prevent concussion is because they are not able to meet this performance requirement. ${ }^{43}$ Another reason is that helmets are not specifically designed to manage angular acceleration or velocity.

The mean maximum resultant angular accelerations for the concussion and no-injury cases in the current study were 7951 (SD $3562 \mathrm{rad} / \mathrm{s}^{2}$ ) and $4300 \mathrm{rad} / \mathrm{s}^{2}$ (SD $3657 \mathrm{rad} / \mathrm{s}^{2}$ ), respectively (figure 2 ). The value for concussion cases, $7951 \mathrm{rad} / \mathrm{s}^{2}$, was slightly higher than the range reported by previous studies, 5022-7912 $\mathrm{rad} / \mathrm{s}^{2}$ (table 2); however, only the ATD reconstruction study by Newman et $a l^{6-8}$ and four instrumented helmet studies $^{16} 212324$ reported angular acceleration results. The value for no-injury cases, $4300 \mathrm{rad} / \mathrm{s}^{2}$, was substantially higher than the values reported by the instrumented helmet studies of Broglio et $a l^{21}$ and Rowson et $a l^{24}$ $1627 \mathrm{rad} / \mathrm{s}^{2}$ and $1230 \mathrm{rad} / \mathrm{s}^{2}$, respectively (table 2), which may again reflects the strong influence of the no-injury case selection criteria. In addition to the mean peak resultant angular acceleration of the head, significant differences $(\mathrm{p}<0.001)$ between concussion and no-injury head impacts were observed for coronal and transverse components (figure 3). The mean peak coronal and transverse angular acceleration of the head, for the concussion cases, were 4823 (SD $2096 \mathrm{rad} / \mathrm{s}^{2}$ ) and $5144 \mathrm{rad} / \mathrm{s}^{2}$ (SD $\left.2800 \mathrm{rad} / \mathrm{s}^{2}\right)$, respectively. Duma et $a l^{13}$ recorded a single concussion case during an instrumented helmet study and reported the peak coronal angular acceleration of $5600 \mathrm{rad} / \mathrm{s}^{2}$; however, the transverse component was not reported. Rowson et $a l^{25}$ reported the mean values of angular acceleration components during 1712 collegiate American football head impacts where no-injury was recorded. Angular acceleration components in all three directions were much lower than the values reported in the current study, which again illustrates the strong influence of the no-injury case selection criteria and the differing nature of the two football codes.

Based upon the logistic regression analyses, angular acceleration of the head in the coronal plane had the strongest association with concussion (table 3). This parameter was both sensitive and specific, with percentage correct classifications for no-injury and concussion cases of $92.3 \%$ and $92.6 \%$, respectively. The values for a $50 \%$ and $75 \%$ likelihood of concussion were 1747 and $2296 \mathrm{rad} / \mathrm{s}^{2}$, respectively. The resultant and coronal components of mean peak angular velocity were also associated with concussion. This provides some support to the hypothesis by Holbourn ${ }^{29}$ that rotational kinematics are the main cause of shear strains in the tissue of a particular region of the brain and, therefore, indicative of the probability of injury in that region; however, brain tissue loading was not assessed in this study. This demonstrates that there are impact direction sensitivities, for example, angular head acceleration in the coronal plane, which may be useful to consider in order to improve the predictive capabilities of instrumented helmets and in systems to prevent brain injury. ${ }^{19}$ It must be acknowledged that while associations exist between component accelerations and concussion, all cases in the current study involved a direct head impact and combinations of linear and angular head accelerations. The use of FE and other modelling methods will lead to a better understanding of the role of the component accelerations on brain loading in concussion. In addition, methods that combine linear and angular head kinematics in a single measure are important. Newman et $a l^{6} 744$ developed both the Head Impact Power (HIP) and the Generalized Acceleration Model for Brain Injury Threshold (GAMBIT) criteria; however, they were not examined in this paper as HIP was previously analysed by Fréchède and McIntosh, ${ }^{28}$ while GAMBIT lacks validation and is seldom used as an index for head injury. $^{45}$

No previous study has performed logistic regression analyses for individual kinematic components; however, Greenwald et $a l^{19}$ used principal component analysis to develop a new composite variable, weighted principal component score (wPCS), for use in predicting concussion. It was found that the wPCS head impact severity measure, which accounts for impact location, was more predictive than classical measures, such as the resultants 
of linear and angular acceleration. Rowson $e t a l^{24}$ carried out linear regression analyses for the rotational kinematic resultants. In the current study, a value of $6633 \mathrm{rad} / \mathrm{s}^{2}$ for peak angular acceleration was found to be associated with a $75 \%$ likelihood of concussion (table 3), which compared well to the value of $6945 \mathrm{rad} / \mathrm{s}^{2}$ reported by Rowson et $a .^{24}$ The maximum change angular velocity value for a $75 \%$ likelihood of concussion, $27.5 \mathrm{rad} / \mathrm{s}$, found in the current study, also compared well to the value of $30.8 \mathrm{rad} / \mathrm{s}$ reported by Rowson $e t a l^{24}$ Although there were differences in the range head accelerations measured between sports and cohorts, there were strong similarities. This finding suggests that common human tolerance values can be used to design equipment to prevent concussion for all sports.

The main limitations of the current study stem from the reconstruction process and the limited sample size. McIntosh $e t a l^{26}$ identified the closing velocity estimation error to be approximately $10 \%$; however, the closing velocities were only used as initial estimates for the rigid body reconstructions and the frame-by-frame analysis was used to manage this error. Fréchède and McIntosh ${ }^{27}$ carried out a sensitivity analysis of possible errors and identified initial position and velocity of the players were the most influential parameters. The contact properties of the head were also found to be an influential parameter, with the error minimised through evaluation against a range of experimental boundary conditions from the literature. The contact properties of the head were refined and validated using data from cadaver impact experiments and FE simulations. ${ }^{33-35}$ The sensitivity analysis suggested that the influence of neck muscle activation, for example, bracing for impact, on head dynamics was less than that of boundary conditions such as initial position and velocities. ${ }^{27}$ It is acknowledged that this influence may vary between impact scenarios; however, it was not possible to draw reliable conclusions from the videos regarding a state of awareness and subsequent level of muscular activation. A compromise was made by selecting to model a state of standard awareness, which was achieved by providing enough resistance in the joints to counter the effects of gravity. It is acknowledged that compounding errors may be manifested during the reconstruction process; however, due to large interscenario variability among simulation cases, no compounding error estimates could be made. The sample size was limited by resources, the laborious process of reconstruction and the quality of the video. For future studies it would be advantageous to obtain all video feeds, not just the broadcast video. Another limitation is that some signs of concussion are transient and may be missed on video review and by team physicians. Although no no-injury case was recorded contemporaneously as being concussed, the possibility remains that this was undiagnosed or unreported. A valuable area of novel research would be to develop a reliable, valid and practical method for instrumenting unhelmeted athletes. Such studies would be further enhanced by collecting a broader range of clinical, neuropsychological and radiological data for all head impact cases, both concussion and no-injury.

The results support the hypothesis proposed by Holbourn $^{29}$; showing strong associations between angular kinematics of the head, in the coronal plane, and concussion. These associations have practical implications for concussion research and management. First, kinematic parameters can be measured in physical tests and in equipment tests to assess injury reduction potential. By considering relevant injury mechanisms, human tolerance values, pass-fail criteria for a device and impact severity, a test method can be developed that provides a performance target for equipment manufacturers and policy makers. ${ }^{32}$ Second, the kinematic parameters can also be measured within a helmet or head mounted package, which provides opportunities for on-field monitoring and/or research, as evidenced already by the wide use of instrumented helmets. ${ }^{13-24}$ Finally, observation of where the player is struck in the head may assist sideline management of concussion, where other technologies are absent.

\section{Author affiliations}

${ }^{1}$ Australian Centre for Research into Injury in Sport and its Prevention, Federation University Australia, Ballarat, Australia

${ }^{2}$ Monash Injury Research Institute, Monash University, Melbourne Australia

${ }^{3}$ Faculty of Science, University of New South Wales, Sydney, Australia

${ }^{4}$ Université de Lyon, F-69622, Lyon, France

${ }^{5}$ Université Claude Bernard Lyon 1, Villeurbanne

${ }^{6}$ IFSTTAR, UMR_T9406, LBMC, F-69675, Bron

${ }^{7}$ Techspace Aero, Safran Group Milmort, Belgium

${ }^{8}$ Centre d'Expertise en Dynamique Rapide, Explosions et Multiphysique (CEDREM), Ecoparc d'Affaires de Sologne, Domaine de Villemorant,

Neung-sur-Beuvron, France

${ }^{9}$ Stryker GmbH \& Co, Duisburg, Germany, Belgium

Contributors All authors made substantial contributions to the conception or design of the work; or the acquisition, analysis or interpretation of data for the work; drafting the work or revising it critically for important intellectual content; final approval of the version to be published and agreement to be accountable for all aspects of the work in ensuring that questions related to the accuracy or integrity of any part of the work are appropriately investigated and resolved. In addition, ASM planned the study and supervised the programme of research; $B F$ developed and supervised aspects of the computer simulations; P-AP, EF, TO and DAP reconstructed and simulated the cases; and, ASM and DAP undertook the initial data analysis.

Funding This research received no specific grant from any funding agency in the public, commercial or not-for-profit sectors.

Competing interests ASM is a lead researcher at the Australian Centre for Research into Injury in Sport and its Prevention (ACRISP). ACRISP is one of the designated International Olympic Committee centres for research into the prevention of injury and protection of athlete health. The research reported in this paper was unfunded. All authors were at the time either employees of the University of New South Wales (ASM and BF), research students (DAP) or practicum students at UNSW supervised by ASM (P-AE, EF, TO). The assistance of Dr Paul McCrory in providing video is gratefully acknowledged. The original data are stored in the Faculty of Science at UNSW. Preliminary results related to this study were presented by ASM, BF, PM, EF, TO and P-AP. Biomechanics of concussion in sport-differences between injury and non-injury cases, at the 2009 Australian Conference of Science and Medicine in Sport, the Seventh National Physical Activity Conference and the Sixth National Sports Injury Prevention Conference, Brisbane 14-17 October 2009. The short abstract from that conference presentation is published in the $J \mathrm{Sci}$ Med Sport, 2009, 12, Supplement: 155. 
Ethics approval University of New South Wales Human Research Ethics Advisory Panel (No. 08/2009/51).

Provenance and peer review Not commissioned; externally peer reviewed.

Data sharing statement No additional data are available.

Open Access This is an Open Access article distributed in accordance with the Creative Commons Attribution Non Commercial (CC BY-NC 3.0) license, which permits others to distribute, remix, adapt, build upon this work noncommercially, and license their derivative works on different terms, provided the original work is properly cited and the use is non-commercial. See: http:// creativecommons.org/licenses/by-nc/3.0/

\section{REFERENCES}

1. McCrory PR. The nature of concussion: a speculative hypothesis. $\mathrm{Br}$ J Sports Med 2001;35:146-7.

2. Gordon KE, Dooley JM, Wood EP. Descriptive epidemiology of concussion. Pediatr Neurol 2006;34:376-8.

3. Erlanger DM, Kutner KC, Barth JT, et al. Neuropsychology of sports-related head injury: dementia pugilistica to post concussion syndrome. Clin Neuropsychol 1999;13:193-209.

4. McCrory PR, Meeuwisse WH, Aubury M, et al. Consensus statement on concussion in sport: the 4th International Conference on Concussion in Sport held in Zurich, November 2012. Br J Sports Med 2013;47:250-8.

5. Ommaya AK, Gennarelli TA. Cerebral concussion and traumatic unconsciousness: correlation of experimental and clinical observations on blunt head injuries. Brain 1974;97:633-54

6. Newman JA, Beusenberg MC, Fournier E, et al. A new biomechanical assessment of mild traumatic brain injury: part 1-Methodology. International Research Council on the Biomechanics of Impact Conference. Sitges, Spain: IRCOBI, 1999:17-36.

7. Newman JA, Barr C, Beusenberg MC, et al. A new biomechanical assessment of mild traumatic brain injury: part 2-Results and conclusions. International Research Council on the Biomechanics of Impact Conference. Montpellier, France: IRCOBI, 2000:223-33.

8. Newman JA, Beusenberg MC, Shewchenko N, et al. Verification of biomechanical methods employed in a comprehensive study of mild traumatic brain injury and the effectiveness of American football helmets. J Biomech 2005;38:1469-81.

9. Pellman EJ, Viano DC, Tucker AM, et al. Concussion in professiona football: part 1-reconstruction of game impacts and injuries. Neurosurg 2003;53:799-814.

10. Zhang L, Yang KH, King Al. A proposed injury threshold for mild traumatic brain injury. J Biomech Eng 2004;126:226-36.

11. Kleiven S. Predictors for traumatic brain injuries evaluated through accident reconstructions. Stapp Car Crash J 2007;51:81-114.

12. Naunheim RS, Standeven J, Richter C, et al. Comparison of impact data in hockey, football, and soccer. J Trauma 2000;48:938-41.

13. Duma SM, Manoogian SJ, Bussone WR, et al. Analysis of real-time head accelerations in collegiate football players. Clin J Sports Med 2005;15:3-8.

14. Brolinson PG, Manoogian SJ, McNeely D, et al. Analysis of linear head accelerations from collegiate football impacts. Curr Sports Med Rep 2006;5:23-8.

15. Funk JR, Duma SM, Manoogian SJ, et al. Development of concussion risk curves based on head impact data from collegiate football players. Injury Biomechanics Research: 34th International Workshop. Dearborn, MI, USA, 2006:1-15.

16. Guskiewicz KM, Mihalik JP, Shankar V, et al. Measurement of head impacts in collegiate football players: relationship between head impact biomechanics and acute clinical outcome after concussion. Neurosurg 2007;61:1244-53.

17. McCaffrey MA, Mihalik JP, Crowell DH, et al. Measurement of head impacts in collegiate football players: clinical measures of concussion after high- and low-magnitude impacts. Neurosurg 2007;61:1236-43.

18. Schnebel B, Gwin JT, Anderson S, et al. in vivo study of head impacts in football: a comparison of National Collegiate Athletic Association Division I versus high school impacts. Neurosurg 2007;60:490-6.
19. Greenwald RM, Gwin JT, Chu JJ, et al. Head impact severity measures for evaluating mild traumatic brain injury risk exposure. Neurosurg 2008;62:789-98.

20. Broglio SP, Sosnoff JJ, Shin SH. Head impacts during high school football: a biomechanical assessment. J Athl Train 2009;44:342-9.

21. Broglio SP, Schnebel B, Sosnoff JJ, et al. Biomechanical properties of concussions in high school football. Med Sci Sport Exerc 2010;42:2064-71.

22. Crisco JJ, Fiore R, Beckwith JG, et al. Frequency and location of head impact exposures in individual collegiate football players. $J$ Ath Train 2010;45:549-59.

23. McAllister TW, Ford JC, Ji S, et al. Maximum principal strain and strain rate associated with concussion diagnosis correlates with changes in corpus callosum white matter indices. Ann Biomed Eng 2012;40:127-40.

24. Rowson S, Duma SM, Beckwith JG, et al. Rotational head kinematics in football impacts: an injury risk function for concussion. Ann Biomed Eng 2012;40:1-13.

25. Rowson S, Brolinson PG, Goforth MW, et al. Linear and angular head acceleration measurements in collegiate football. J Biomech Eng 2009;131:1-7.

26. McIntosh AS, McCrory PR, Comerford J. The dynamics of concussive head impacts in rugby and Australian rules football. Med Sci Sport Exerc 2000;32:1980-4.

27. Fréchède $B$, McIntosh AS. Use of MADYMO's human facet model to evaluate the risk of head injury in impact. 20th International Technical Conference on the Enhanced Safety of Vehicles. Lyon, France: NHTSA, 2007:1-14.

28. Fréchède $B$, Mclntosh AS. Numerical reconstruction of real-life concussive football impacts. Med Sci Sport Exerc 2009;41:390-8.

29. Holbourn AHS. Mechanics of head injuries. Lancet 1943;242:438-41

30. Hardy WN, Mason MJ, Foster CD, et al. A study of the response of the human cadaver head to impact. Stapp Car Crash J 2007;51:17-80.

31. Rowson S, Duma SM. Brain injury prediction: assessing the combined probability of concussion using linear and rotational head acceleration. Ann Biomed Eng 2013;41:873-82

32. Mclntosh AS, Andersen TE, Bahr R, et al. Sports helmets now and in the future. Br J Sports Med 2011;45:1258-65.

33. Mclntosh AS, Kallieris D, Mattern R, et al. Head and neck injury resulting from low velocity direct impact. 37th Stapp Car Crash Conference. San Antonio, TX, USA: SAE, 1993:43-57.

34. Neale M, McGrath M, Baumgartner D, et al. Comparative study between finite element human and dummy head model responses under impact. International Research Council on the Biomechanics of Impact Conference. Graz, Austria: IRCOBI, 2004.

35. Yoganandan N, Pintar FA, Sances A Jr, et al. Biomechanics of skull fracture. J Neurotrauma 1995;12:659-68.

36. Cheng $\mathrm{H}$, Obergefell L, Rizer A. The development of the GEBOD program. 15th Southern Biomedical Engineering Conference. Dayton, OH, USA: IEEE, 1996:251-4.

37. SPSS Inc. PASW Statistics. 2009: Chicago, IL, USA.

38. Peng C-YJ, Lee KL, Ingersoll GM. An introduction to logistic regression analysis and reporting. J Educ Res 2002;96:3-14.

39. Bewick V, Cheek L, Ball J. Statistics review 14: logistic regression. Crit Care 2005;9:112-18.

40. Menard S. Applied logistic regression analysis. Quantitative applications in the social sciences. Thousand Oaks, CA, USA: Sage, 1995

41. Nagelkerke NJD. A note on a general definition of the coefficient of determination. Biometrika 1991;78:691-2.

42. Benson BW, Mclntosh AS, Maddocks D. What are the most effective risk reduction strategies in sport concussion? From protective equipment to policy. Br J Sports Med 2013;47:321-6.

43. Mclntosh AS, McCrory PR, Finch CF, et al. Does padded headgear prevent head injury in rugby union football? Med Sci Sport Exerc 2009;41:306-13.

44. Newman JA. A generalized acceleration model for brain injury threshold (GAMBIT). International Research Council on the Biomechanics of Impact Conference. Zurich, Switzerland: IRCOBI, 1986:121-31.

45. Schmitt K-U, Niederer PF, Muser MH, et al. Head injuries. In: Trauma biomechanics: accidental injury in traffic and sports. 2nd edn. New York, NY, USA: Springer, 2007:55--81. 